\title{
Instituições militares também aprendem? Uma revisão bibliográfica sobre abordagens organizacionais na gestão de defesa ${ }^{1}$
}

\author{
Tamiris Pereira dos Santos ${ }^{\mathrm{I}}$ (D) \\ Érico Esteves Duarte ${ }^{\mathrm{II}}$
}

\section{Introdução}

A história política contemporânea do Brasil tem cobrado que uma parte substantiva da produção das ciências sociais brasileiras fosse focada nas relaçóes civis-militares, principalmente no contexto da redemocratização a partir dos anos 1980. Após uma relativa harmonia entre esferas civis e militares no país, a instabilidade política contínua pela qual o país passa, pelo menos desde 2013, tem tido, mais e mais, o estamento militar como protagonista. Muitos dos vícios identificados no passado de envolvimento militar na vida política parecem ter reemergido, fator que demanda atualizaçóes nas pesquisas sobre relaçóes civis-militares.

A produção acadêmica sobre as relaçóes civis-militares segue, em boa medida, a abordagem inaugurada por Huntington (1956) cujo foco dos estudos, particularmente sobre o envolvimento desestabilizador de militares na política, se dá a partir das estruturas institucionais e política da sociedade em vez de compreender de maneira mais específica as características sociais e organizacionais das forças armadas (Huntington, 1956, p. 194). A principal consequência negativa desta configuração é que o controle objetivo das forças armadas através de sua profissionalização é abordado de forma marginal por estudos com bases analíticas inconsistentes e limitadas em efetivas propostas de orientação política (Bruneau, 2018). Numa última apreciação do estado desse campo (Pion-Berlin; Dudley, 2020), é chocante que os estudos sobre golpes militares (por exemplo, Barany, 2012; Hebditch; Connor, 2009; Luttwak, 2016) ainda sejam os mais operacionalizáveis como agenda executiva.

Uma apreciação da produção brasileira leva a constatação de que, com algumas exceçóes, como por exemplo Costa (1998), que já sugeria direcionamentos em prol da maior inserção de civis e militares no âmbito educacional, e de Silva (2007), que nos brinda com análises e proposiçôes sobre mudança organizacional envolvendo o processo político-orçamentário da Marinha, tal produção aparentemente padece de um problema em comum: ao passo que possui um conteúdo normativo muito expressivo em prol da democratização das relaçôes civis-militares e problematizaçóes sobre o processo de controle civil desde a criação do Ministério da Defesa, seu enquadramento analítico é excessivamente descritivo e insuficiente como subsídio de políticas públicas ou agência estatal relacionada

1 A pesquisa deste artigo foi financiada por uma bolsa de pesquisa de produtividade do CNPq e por uma bolsa de pós-doutorado do edital PROCAD-Defesa.

\footnotetext{
IPrograma de Pós-Graduação em Estudos Estratégicos Internacionais (PPGEEI), Universidade Federal do Rio Grande do Sul (UFRGS) - Porto Alegre (RS), Brasil. Email: tpsantos88@gmail.com

IIFaculdade de Ciências Econômicas, Universidade Federal do Rio Grande do Sul (UFRGS) - Porto Alegre (RS), Brasil. E-mail: erico.duarte@ufrgs.br

Recebido em: 08/07/2020. Aprovado em: 26/05/2021.
} 
aos militares (Proença Júnior, 2011). Apesar de compartilhar o conteúdo normativo da literatura brasileira sobre relaçóes civis-militares, apontamos que a institucionalização destas relaçôes precede e condiciona sua democratização de fato. E é este argumento que justifica e orienta o presente artigo.

Nesse sentido, a análise organizacional das forças armadas no Brasil ainda não consiste em um subcampo dos estudos de relaçôes civis-militares, por uma diversidade de fatores; seja porque ainda existe todo um caminho a ser percorrido no seu desenvolvimento, seja porque estamos tratando deste assunto em uma democracia ligeiramente jovem, cujos desafios nas relaçôes entre civis e militares em termos de responsabilização, transparência e maturidade institucional ainda estáo em tela (Ratchev, 2011). Outro ponto a ser considerado é a própria construção dessa agenda de pesquisas, que, por não desfrutar de um amparo acadêmico mais robusto, vem avançando de maneira quase artesanal, construindo um verdadeiro "mosaico de contribuiçôes".

Para agregar mais uma peça neste mosaico, o que se pretende abordar neste artigo, de maneira ilustrativa e comparada, são basicamente dois pontos:

1. Se instituiçôes militares são capazes "de aprender e evoluir", principalmente sob orientaçáo e em correspondência com os interesses e normas civis;

2. Quais abordagens, para além da discussão de cultura organizacional, podem ser utilizadas, expandindo o escopo de análise para criarmos um arcabouço teórico-funcional direcionado à gestão e ao controle das forças armadas.

Abordagens organizacionais, comumente utilizadas em outros campos de estudo das ciências humanas aplicadas, como a administração, podem ser ferramentas bastante elucidativas no que tange a temas como mudança organizacional, aprendizado e dinâmicas envolvidas na evolução e transformação das organizaçôes de defesa, tanto civis quanto militares. Ou seja, existe uma pluralidade de abordagens teóricas com as quais é possível se estabelecer um diálogo para que perspectivas mais acuradas sobre processos, relaçóes e determinados padróes sejam visualizados no âmbito da gestão.

No entanto, é preciso ter em tela que apesar de tratarmos de administração na esfera pública, ao mencionarmos defesa e mudanças organizacionais, lidamos com uma série de peculiaridades inerentes a uma esfera exposta a diferentes dinâmicas coexistentes a saber, corpo de civis e de militares. Apesar de a defesa ser parte administrável da esfera pública, sua implementação apresenta componentes que a distinguem de outras pastas em termos de política, planejamento e gestão (Pessoa; Duarte, 2014).

Convém acrescentar que a despeito de não nos aprofundarmos tanto nas diferenças mencionadas, o nosso objetivo neste artigo é apresentar uma breve revisão bibliográfica que contemple algumas das principais abordagens organizacionais e ilustre de maneira comparada suas diferenças e potenciais de análise. Comparando abordagens sistêmicas e abordagens mais planificadas, a ideia é apresentar que, em termos teóricos, a literatura dialoga e possui vários insumos para que os desafios em torno do processo de mudança organizacional no meio militar fiquem mais claros, possibilitando melhorias de gestão. Desta maneira, o artigo está organizado sete seçôes:

- A próxima seção propóe a organização da literatura sobre mudança e aprendizado organizacional em instituiçôes militares em cinco grupos de abordagens: cultura organizacional, burocracia política, aprendizado organizacional, inovação militar e uma leitura crítica a respeito da teoria organizacional; 
- As cinco seçôes seguintes inspecionam cada uma dessas abordagens e as discussôes correlatadas sobre suas respectivas propriedades e limites;

- Nas consideraçóes finais, o artigo resgata os principais pontos realizados neste exercício de revisão bibliográfica e tece conclusôes a respeito destes, sua contribuição e os desafios de gestáo organizacional das instituições militares.

\section{Mudanças, aprendizados e diferentes abordagens}

Apesar de instituiçóes conhecidas pela sua rigidez hierárquica, as quais tipicamente apresentam maior resistência a mudanças, há que se ressaltar que a questão da dinâmica organizacional de forças armadas nas relaçóes com instituiçóes civis vem sendo destacada como uma variável fundamental para a efetividade militar (Brooks; Stanley, 2007; Feaver, 2017).

Isso tanto é aplicável, que é possível observar a evoluçâo das forças armadas contemporâneas como um sistema (Biddle, 2006), quanto como o equilíbrio das relaçôes civis-militares vêm moldando a formaçáo dos Estados ou novos ordenamentos (Buzan; Little, 2000; Kadercan, 2014).

Entretanto, convém incluir que estes não foram os únicos aspectos em que é possível observar a mudança e a gestáo dos estamentos militares. A maturidade institucional das forças armadas em vários âmbitos, como o educacional, também abarca diversas instâncias de desenvolvimento, desde a relação entre civis e militares, até uma abertura para a emergência de uma nova lógica organizacional. Autores como Libel (2010) e Syme-Taylor (2010) abordam a experiência das forças armadas britânicas, ilustrando os desafios que fizeram parte de um emprego de novos métodos pedagógicos dentro de sua academia de defesa, envolvendo um aprofundamento da presença civil nesta instituição.
Neste sentido, compreendemos que o desafio a se considerar para a gestão das forças armadas consiste em observar para além da cultura castrense como vetor de mudanças organizacionais, exercício para o qual convidamos os leitores neste artigo. As abordagens são diversas; Davidson (2010) localizou que algumas delas possuem maior enfoque sobre a mudança organizacional em si, outras destacam o aprendizado organizacional, mas também há as que versam de forma integrada sobre a mudança militar e, por fim, existem abordagens sobre cultura organizacional. Todas compóem uma constelação de perspectivas específicas para analisar, cada qual a sua maneira, quais as barreiras devem ser vencidas para a instauração das inovaçóes e seus respectivos contextos (Davidson, 2010).

Se formos subdividir as contribuiçôes que aqui trazemos conforme categorias localizadas por Davidson (2010), temos:

- Cultura organizacional - com autores como Kier (1996) e Nagl (2002);

- Burocracia política - representada pelos trabalhos como Allison e Zelikow (1999) e Halperin, Clapp e Kanter (2006);

- Mudança militar como aprendizado organizacional-com autores como a própria Davidson (2010); Baird, Henderson e Watts (1997); DiBella (2010); Kolb e Kolb (2008); Nagl (2002); Segal e Segal (1983) e Senge (1994);

- Teorias integradas sobre inovaçáo militarcom autores que variam suas ênfases entre inovação militar, como Posen (1986) e Rosen (1991), alguns aspectos culturais apregoados por Kier (1996), Murray (1996), e analistas de aspectos entre sua inovação e a difusão, como Horowitz (2007);

- Revisão crítica da Teoria Organizacionalque, apesar de se constituir no grande ramo do qual derivam todas as perspectivas aqui mencionadas, inclui autores com abordagens mais abrangentes, 
como Stulberg, Salomone e Long (2007), em um processo que pode ser entendido em parte como uma atualização do enfoque de Feaver (2003).

Entre pontos de concordâncias e discordâncias, as abordagens teóricas organizacionais tendem a apontar as dificuldades inerentes ao processo de mudança organizacional dentro de instituiçôes militares, seja devido às resistências já citadas, seja por conta de outros tipos de barreiras; o que varia em cada uma, em termos gerais, são quais questionamentos são respondidos, ou seja, qual é a variável principal a ser analisada e a solução possível.

Para Davidson (2010, p. 19), existem questionamentos que não são passíveis de serem respondidos fora do âmbito da abordagem do aprendizado organizacional, como, por exemplo, "de que forma as novas ideias são aproveitadas, como são transferidas para a organização como um todo, quais os processos pelos quais a esfera militar aprende e muda [... $]^{\prime 2}$. No entanto, as abordagens integradas acerca da inovaçáo militar se ocupam em explicitar contextos, como as mudanças são traduzidas e repassadas para a organizaçăo sob a forma de doutrinas, entre outros pontos abordados por Posen (1986) e Rosen (1991). A questão que nos norteia aqui, em termos de contribuição para as análises de gestão das forças armadas, assim como a organização do conteúdo e os parâmetros de comparação, é se organizaçóes militares são passíveis de aprendizado organizacional ou se há outros fatores motrizes para a mudança organizacional.

Para tanto, seguiremos apresentando as diferentes abordagens mencionadas anteriormente, ilustrando de maneira breve as contribuiçóes que os autores reunidos trouxeram em cinco seçôes. Posteriormente, um quadro demonstrará suas semelhanças e diferenças para efeito de análise comparativa.

\section{Cultura organizacional: entre aprendizado e doutrina}

Começando pela abordagem mais amplamente discutida na área de estudos sobre forças armadas, a cultura organizacional é uma das variáveis mais observadas junto aos estudos de doutrina. Propondo uma abordagem complementar à visão de Posen (1986) em que o comportamento militar seria variável dependendo da doutrina escolhida, Kier (1996) propóe um modelo para que a doutrina militar possa ser melhor compreendida por meio de sua cultura organizacional e náo apenas por meio de sua natureza ofensiva ou defensiva.

Segundo Kier (1996), restringir a análise dos fatores que originam a doutrina militar apenas às dinâmicas da balança de poder é um movimento que deixa de captar as influências da participação civil no processo, além do ambiente externo em termos de contexto. A abordagem da autora basicamente busca captar como a cultura afeta o processo decisório civil e militar na formação da doutrina militar, tendo o caso francês antes da $2^{\text {a }}$ Guerra Mundial como base. Segundo a autora, a doutrina militar está relacionada a dois aspectos: os constrangimentos impingidos pela política doméstica e, complementarmente, a cultura organizacional, que seria a variável interveniente entre aquela e os constrangimentos da política doméstica.

Já Nagl (2002) centra sua discussão em como as forças armadas podem aprender e internalizar o conhecimento sob a forma de mudanças na doutrina, apresentando um olhar crítico em relaçáo a autores de teorias integradas sobre a inovação militar. Segundo Nagl (2002), a visão abordada por tais autores não avalia adequadamente como as diferentes forças armadas criam, assimilam e disseminam a mudança das doutrinas ao longo dos 
conflitos, tão pouco a razão de algumas forças serem mais bem-sucedidas no processo do que outras. Neste sentido, de maneira similar a Kier (1996), Nagl (2002) propóe a abordagem da cultura organizacional como variável determinante do aprendizado organizacional. $\mathrm{O}$ autor pode ser considerado tanto no grupo de abordagens relacionado à cultura quanto no grupo de abordagens relacionado à mudança organizacional como aprendizado, já que seus estudos de caso buscam mensurar se houve ou não um aprendizado nas experiências de contra insurgência na Malásia por parte das forças armadas britânicas e americanas. Convém acrescentar que outro conceito central na abordagem do autor, o da "essência das organizaçôes" ${ }^{3}$, deriva da abordagem de Halperin et. al. (2006) - a ser apresentada mais adiante que, juntamente com a cultura, condiciona a absorção das mudanças ou sua negação.

Considerando os diferenciais das duas propostas, apesar de Kier (1996) e Nagl (2002) pautarem as análises em relaçáo à cultura organizacional, o último relaciona esta variável com o aprendizado organizacional, sendo sua pesquisa pautada na maneira como a cultura organizacional influencia no aprendizado organizacional e, consequentemente, culmina na transformação das instituiçôes militares em organizaçôes passíveis de aprender e contemplar mudanças em sua doutrina. Já Kier (1996) centra sua análise no caso francês e busca delimitar a relação causal entre cultura organizacional e mudanças na doutrina em uma tentativa de delinear a dinâmica das subculturas políticas e militares, que, segundo a autora, podem ser concorrentes e determinar a não implementação de mudanças. A abordagem de Kier (1996) abre espaço para que a variável cultura seja também agregada à análise, porém, conforme apresentamos, não é passível de se constituir como uma análise abrangente, questão esta captada por Nagl (2002) ao costurar a abordagem da cultura organizacional com a abordagem do aprendizado organizacional.

\section{A burocracia política e o paradigma da política governamental}

Esta abordagem corresponde ao último modelo formulado por Allison e Zelikow (1999) e é diretamente ligada ao aparato burocrático governamental. Dentro do paradigma da política governamental, conforme apresentam os autores, a principal premissa é que a ação governamental é uma resultante política em nível doméstico, de forma que o que ocorre náo é resultado de uma deliberação para a solução de um problema, mas sim resultados derivados de uma equaçáo complexa que envolve a concessão, o conflito e a confusão de agentes com interesses e influências divergentes, juntamente com as decisóes e açôes derivadas de negociaçôes entre indivíduos pertencentes à esfera governamental.

Dessa forma, a abordagem possui uma estrutura de árvore de decisōes - remetendo ao título do livro The essence of decision - em que confluem açóes em nível doméstico e em nível internacional, demonstrando uma anatomia da forma como os mecanismos burocráticos governamentais se posicionam, assim como sua dinâmica de escolhas, impactos e resultados. No entanto, convém apontar que esta abordagem consiste mais em uma ferramenta usada para iluminar lacunas no desenho da ação governamental e da tomada de decisão do que para desvendar relações, processos e parâmetros em um nível organizacional, carecendo, portanto, de complementos para uma análise ou diagnóstico mais detalhado.

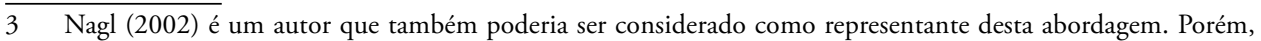
para efeitos de recorte neste artigo, o mencionamos na categoria cultura, optando por trazer mais autores e diversidade de contribuiçóes. 
Se considerarmos que marcos analíticos nada mais são que "esquemas detalhados sobre algum fenômeno” (Ragin, 2007, p. 107), é possível inferir que o trabalho de Allison e Zelikow (1999) tem justamente este mérito: o do ordenamento de marcos analíticos em um modelo em que é possível detectar lacunas com determinada precisão. Porém, na tentativa de reverter os marcos em imagens, o modelo não se autossustenta, visto que as imagens formadas não são completas e não podem ser analisadas em dados ou provas empíricas com a mesma precisão que os marcos foram ordenados. Tampouco é possível que os poucos dados empíricos disponíveis sejam transformados nas imagens a fim de fazer o caminho inverso, isto é, induzir os marcos analíticos deste modelo. Isso se dá, conforme os próprios autores apontaram, porque as informaçóes para depreender a ação política em sua totalidade são muito raramente acessíveis (Allison; Zelikow, 1999; Ragin, 2007). Logo, como um refino do modelo do ator racional e da burocracia weberiana, amplamente adotados nos estudos de relaçóes internacionais e ciência política, o paradigma da política governamental oferece uma estrutura instrumental, mas não demonstra uma teoria a despeito de sua relativa organicidade.

Já a abordagem de Halperin, Clapp e Kanter (2006) busca um objetivo bastante específico: o de compreender o processo burocrático envolvido na tomada de decisóes governamentais no âmbito da segurança nacional, tendo por estudo de caso a questão da instauração do sistema antibalístico (ABM, em inglês), em 1967. Ou seja, trata-se mais uma vez de um arranjo em que a tomada de decisão em si consiste no centro de preocupaçóes e não necessariamente o processo de mudança organizacional, o qual consiste em um processo incidental e subordinado às tomadas de decisão na abordagem dos atores mencionados.

Observam-se alguns avanços em relação ao modelo apresentado por Allison e Zelikow
(1999). Apesar de ambas trazerem como pano de fundo o processo burocrático como arena da tomada de decisão, Halperin, Clapp e Kanter (2006) demonstraram preocupaçáo em compreender a fundo a anatomia deste processo, tomando como estudo de caso a estrutura do sistema presidencial dos EUA. Apesar de a abordagem estar limitada ao regime governamental - já que se trata de uma aplicação do arranjo ao sistema presidencial - e da estrutura burocrática analisada per se, os autores trouxeram conceitos mais aprofundados em termos de peso causal. O conceito de imagem compartilhada e o conceito de essência organizacional, que pode ser associado à cultura organizacional sem maior prejuízo interpretativo, são exemplos disso. Outro ponto a destacar desta última abordagem é a apresentação de estratégias que impóem dificuldades à implementação de decisóes em virtude da atuaçáo de múltiplos agentes, demonstrando que as organizaçóes não são um todo monolítico e que a implementação é passível de dinâmicas que estão além do escopo de atuação dos agentes decisórios da esfera executiva, estando atrelada a uma complexidade que muitas vezes escapa à planificação que se faz em primeira instância nos processos de análise.

Apesar de conterem estes avanços, as limitaçôes desta abordagem se dão em termos de originalidade, posto que basicamente ecoam o arranjo de seus precursores, e padecem em questão similar: a falta de informações adicionais e aplicabilidade geral, independentemente do regime -, por mais que superar estes pontos não tenha sido objetivo dos autores, senáo estabelecer parâmetros, padróes e a anatomia do processo burocrático americano no período posterior à 2a Guerra Mundial. O refino obtido a partir desta abordagem possibilita não apenas agregar outras abordagens organizacionais, mas também aplicar aquilo que Allison e Zelikow (1999) coletaram, possuindo validade como arranjo mesmo fora do contexto americano. 


\section{A mudança organizacional como aprendizado}

A mudança organizacional como aprendizado dentro da esfera militar é uma abordagem que remonta ao período final da Guerra Fria. Como são diversas as abordagens neste sentido, elas serão apresentadas uma a uma com seus principais pontos, premissas e críticas para melhor visualização.

Seguindo a esteira histórica das alteraçóes de paradigmas trazidas pelo período da Guerra Fria, Segal e Segal (1983) buscam analisar as organizaçóes militares e os impactos das mudanças nestas a partir do nível do indivíduo sob uma perspectiva sociológica, considerando questóes sob um prisma psicológico, como a sensação de pertencimento e a oportunidade de autoatualização.

Ao realizarem uma crítica à construção da racionalidade weberiana em estruturas mais rígidas, os autores detectaram que as questóes atinentes ao nível de racionalidade individual também permeiam as organizaçôes de forma consequencial, e esta percepção consiste em uma problemática visível também em organizaçôes militares. Neste sentido, os autores ressaltam a existência de dois modelos organizacionais pautados em arranjos distintos: o modelo tradicional, que enfatiza uma solidariedade de ordem mais mecânica - na qual os laços de afeto e coesão estão fortemente presentes entre os indivíduos das unidades combatentes como valores determinantes da moral das forças - e o modelo orgânico, que é influenciado pela economia e psicologia.

Conforme Segal e Segal (1983, p. 158):

"O modelo mecânico da solidariedade militar foi desenvolvido por disciplinas aprendidas cujos praticantes se estabeleceram em universidades, exceto pelos períodos de mobilização em período de guerra.
O modelo foi, portanto, mais popular fora da arena política do que dentro desta. O modelo orgânico, em contrapartida, foi advogado por disciplinas cujos praticantes há muito sentiram que era legítimo deixar as veredas da academia e se envolverem no processo político: economia e psicologia." ${ }^{\prime 4}$

Por fim, os autores sublinham o fato de que cada instituição é única e que, apesar do incorporar de tendências apresentadas pelas diferenças de abordagem, as instituiçóes militares ficam entre a manutenção da solidariedade social e a tendência à individualizaçâo observada na sociedade. $\mathrm{O}$ avanço da abordagem dos autores, à luz da época, se dá ao diferenciar os estilos de aprendizados e disciplinas ofertadas aos militares, demarcando as diferenças entre o modelo mecânico e o modelo orgânico e, consequentemente, as diferenças de aprendizado. Contudo, em termos de desenvolvimento de uma abordagem mais geral, Segal e Segal (1983) não se aprofundaram na hipótese do aprendizado da instituição militar como propulsor para sua mudança organizacional, deixando este ponto apenas subentendido em sua análise. Em razão disso, a análise se torna pouco conclusiva quanto às orientaçóes tomadas pelas forças armadas em termos de proposição de um modelo analítico e, especialmente, quais alteraçóes ou elementos caracterizaram a adoção por um modelo de mudança organizacional ou outro, demandando complementaçóes.

Já a análise de Senge (1994) se ocupa de como construir uma organização orientada pelo aprendizado por meio de uma visão sistêmica, intitulando os fundamentos para tanto de pensamento sistêmico (systems thinking) ou "quinta disciplina", fazendo análises em uma construção similar à de um manual. $\mathrm{O}$ autor formula algumas leis aplicáveis a esta quinta disciplina a fim de organizar alguns princípios. Alguns exemplos que selecionamos são: 
a. a origem dos problemas atuais se dá por meio das soluçóes anteriormente tomadas;

b. quanto mais se alavanca para uma situação, mais o sistema reagirá contra;

c. causa e efeito não estão relacionados de forma próxima no tempo e no espaço;

d. pequenas mudanças podem produzir grandes resultados (mas as áreas de maior influência são as menos óbvias).

A análise de Senge (1994) busca entender a estrutura do sistema para compreendê-lo por inteiro, de forma a determinar as inter-relaçóes estabelecidas entre as partes e o todo. A justificativa usada pelo autor para o uso desta abordagem é justamente a da complexidade na qual a humanidade se encontra imersa, em meio à massiva produção de informaçôes que entra em descompasso com a capacidade de absorvê-las e compreendê-las. Dada sua interdisciplinaridade, esta abordagem ilustra não apenas inter-relaçóes, como também padróes de mudanças. Sua perspectiva sugere uma visualização ampla do aprendizado organizacional, de maneira a se ter o distanciamento analítico necessário para melhor observação de elementos que compóem as inter-relaçôes. Ao mesmo tempo, ela demanda maior especificidade de informaçóes para se estabelecer o nexo causal entre a estrutura do sistema organizacional e os padróes de inter-relação e mudança (Senge, 1994). Seria como se visualizássemos toda uma constelação e seus componentes, mas a especificidade de cada estrela seria menos perceptível, pois estamos dando maior atenção ao quadro geral (constelação).

$\mathrm{Na}$ abordagem de Baird, Henderson e Watts (1997), a percepção de que a rapidez dos fluxos de informaçóes e sua captação por parte dos indivíduos consiste em um movimento que também se reflete no nível organizacional. Em outras palavras, os autores acreditam que o investimento para que as mudanças de natureza organizacional por meio do aprendizado ocorram deve partir dos recursos humanos, questão que eles sustentam a partir de quatro premissas-chave básicas (Baird; Henderson; Watts, 1997, p. 385-386), em que:

a. é essencial aprender a partir das experiências prévias, documentadas, vivenciadas, dado um ambiente efêmero e incerto;

b. o aprendizado individual e em grupo se tornou o aprendizado organizacional;

c. existem diferenças entre informação e conhecimento. $\mathrm{O}$ aprendizado precisa ser focado na utilidade da informação em açôes;

d. é necessária uma diminuição do tempo de assimilação entre o que foi aprendido e a sua colocação em prática.

O estudo de caso escolhido para a análise foi o Centro de Liçóes Aprendidas do Exército Americano (ou Center for Army Lessons Learned - CALL), o qual estabelece passos que podem ser incluídos no ciclo de aprendizado apresentado pelos autores, em que três etapas fundamentais são delineadas: rastrear - captar aprendizados -; interpretar - sintetizar, analisar e codificar -; e agir - aplicar e compartilhar o aprendizado (Baird; Henderson; Watts, 1997).

Apesar da sistematização dos autores quanto aos processos que permeiam a mudança organizacional por meio do aprendizado e dos impactos específicos ocasionados mediante observação do CALL, a abordagem encontra limitaçóes no âmbito da análise ao configurar mais uma prospecção do que uma busca por questóes determinantes no processo. No entanto, a análise foi centrada no CALL e não tinha maiores objetivos além de compreender o mecanismo lá aplicado. Neste sentido, como representação prospectiva sobre captação de aprendizado e aplicação, a abordagem dos autores constitui uma fonte de reflexóes assertiva ao passo que, como abordagem teórica per se, carece de princípios com aplicação mais visível e passível de replicação para outros casos, o que aconteceria somente com o auxílio de complementaçóes. 
Neste sentido, à luz da experiência em termos gerais, Kolb e Kolb (2008) apresentam a Teoria do Aprendizado Experimental (Experiential Learning Theory - ELT), na qual, mediante revisão bibliográfica de outros autores, apresentam seis proposições básicas:

a. o aprendizado é mais bem concebido como um processo, e náo em termos de resultados;

b. todo aprendizado é um reaprendizado;

c. aprender requer a resoluçáo de conflitos entre modos dialeticamente opostos de adaptação ao mundo;

d. aprender é um processo holístico de adaptação;

e. o aprendizado resulta das transaçóes sinergéticas entre a pessoa e o ambiente;

f. o aprendizado é um processo de criação de conhecimento.

Ou seja, os autores apresentam o aprendizado de maneira cíclica. Traduzindo este ponto para organizaçóes militares, o aprendizado consiste em um processo de "diferenciação e integração, focado na maestria do ambiente organizacional"5 (Kolb; Kolb, 2008, p. 33). Ou seja, a organização militar possui diferenciaçóes em seu âmbito interno através das unidades especializadas, que se encarregam de lidar com um aspecto do ambiente organizacional, culminando em uma necessidade interna de integração e coordenação. Tal necessidade deriva das diferentes formas que cada unidade especializada desenvolve ao trabalhar, seus diferentes estilos de aprendizado, solução de problemas e tomada de decisão. Dessa maneira, Kolb e Kolb (2008) afirmam que um dos mecanismos de integração entre as unidades militares de uma mesma organização é o estabelecimento de uma mentalidade predominante na cultura organizacional:
"As organizações possuem numerosas formas de atingir a integração como gestão estratégica, visão, liderança, cultura organizacional e equipes multifuncionais. Todos estes mecanismos foram projetados para resolver conflitos entre as unidades especializadas e atingir uma direção coerente para a organização. Muito frequentemente esta integração é atingida por meio da dominância de uma mentalidade funcional na cultura organizacional” (KOLB; KOLB, 2008, p. 33-34).

Como consequência, a partir da perspectiva da ELT, o aprendizado organizacional requer um esforço de valorização e integração de perspectivas diametralmente opostas como a ação e a reflexão, o envolvimento concreto e o desprendimento analítico, a fim de originar um processo que siga toda a lógica cíclica do aprendizado, adaptando-se aos novos desafios impostos pelo ambiente (Kolb; Kolb, 2008).

Apesar de se constituir como uma apresentação mais sistêmica e com uma abordagem mais holística, contando com características interdisciplinares e gerais também aplicáveis a estudos de caso, a ELT não abrange estruturalmente mecanismos explicativos que compreendam as barreiras do aprendizado organizacional para além da capacidade de integração entre os diferentes estilos no ciclo do aprendizado, ou, ainda, nas formas de integração entre as unidades especializadas de uma organização militar. Essa lacuna explicativa se dá devido ao distanciamento provido pela ELT a fim de enxergar as inter-relaçóes presentes no processo de aprendizado, à semelhança do que ocorreu com a abordagem de Senge (1994).

A partir deste ponto, agregando perspectivas mais aplicadas dentro do escopo das instituiçóes militares especificamente, apresentamos as abordagens de DiBella (2010) e Davidson (2010). DiBella (2010; 2013) assevera a ausência de uma teoria geral a respeito de 
efetividade nas organizaçôes militares quanto a própria limitação do modelo por ele proposto, cujo estudo de caso foi o Exército dos EUA. Ainda assim, as organizaçóes militares seriam passíveis de mudança mediante aprendizado a partir de uma visão integrada. Esta visão compreende três itens: o reconhecimento da capacidade de aprendizado, um perfil específico com os objetivos estratégicos da instituição, e, por fim, um plano de gestão de mudanças. Desse modo, como se fossem peças de um quebra-cabeça, o autor presume que as capacidades de aprendizado pelos militares são definidas pelos fatores facilitadores e as orientaçôes de aprendizado (Learning Orientations - LORs), as quais se revelam como reflexos de padróes em que a organização molda seu aprendizado.

As orientaçóes de aprendizado consistem em um conjunto de reflexos que revela padrões pelos quais uma organização molda seu processo de aprendizagem, sendo que cada uma das orientaçóes pode apresentar diferentes possibilidades de abordagem, conferindo tônicas diferentes ao processo de produção e disseminação de conhecimento, conteúdo, reserva, cadeia de valores, o escopo e o foco conferido ao próprio aprendizado (DiBella, 2010). Desenvolvendo sua análise nestes escopos, problematiza-se o referido processo no Exército dos EUA elucidando as dicotomias presentes em termos de novas atribuiçóes que outros contextos e tempos têm trazido para as forças armadas, imbuindo a essas organizaçóes a prerrogativa de promover novas formas de trabalho, repensando o que fazer, porque e como a partir da pesquisa.

A visão integrada proposta pelo autor difere de outras abordagens organizacionais pelo fato de que é orientada especificamente para a movimentação em prol de objetivos estabelecidos, tendo por base a colaboração e/ou a integração das estruturas organizacionais internas - de forma similar ao apregoado por Kolb e Kolb (2008) na aplicação da ELT. Além disso, a abordagem se constitui como uma forma de observar o processo de mudança como mecanismo de possibilidade de passos incrementais em vez da visão linear de estágios de desenvolvimento (DiBella, 2013, p. 18). Neste sentido, a formulaçáo integrada de DiBella $(2010 ; 2013)$ consiste em uma ferramenta para apontar naturezas de mudanças organizacionais nas forças armadas por meio de interaçóes entre fonte de conhecimento e o escopo do aprendizado. Contudo, o desafio de dirimir as diferenças de visóes apresentadas entre diferentes forças singulares de um mesmo país a fim de se permitir a mudança organizacional per se ainda se encontra sem solução dentro deste arranjo.

Por fim, a formulação de Davidson (2010) constitui uma inter-relação entre o papel da cultura organizacional no processo de aprendizado organizacional e da experiência, praticamente representando uma soma das contribuiçóes apresentadas, guardadas as devidas proporçôes. Retomando acepçôes acerca do papel da cultura conforme apresentado por Nagl (2002), a autora depreende que o histórico de uma organização militar afeta diretamente o desenvolvimento de seu perfil. Por conseguinte, isto também afeta a capacidade da organização de aprender a partir de novas experiências (Davidson, 2010), revelando uma tendência que pode ser resumida em predisposição organizacional às mudanças segundo a cultura organizacional vigente, ecoando em boa parcela das formulaçóes teóricas acerca do aprendizado organizacional.

A autora se apoia não apenas no conceito do ciclo de aprendizado organizacional e no papel cumprido pela cultura, como também busca compreender como se dá o aprendizado em termos de processo, avaliando se foi concluído com sucesso ou não. Desse modo, outras variáveis a serem agregadas no ciclo acima são: 
a. o aprendizado experimental, individual ou em grupo, como meio de trazer diferentes luzes e interpretaçóes para o reconhecimento da necessidade de mudança;

b. o aprendizado geracional, cuja principal questão é como indivíduos em pontos similares de desenvolvimento dão sentido coletivamente às suas experiências, levando tais liçóes ao nível organizacional;

c. como redes informacionais e comunidades de práticas levam ao compartilhamento de ideias e experiências impactam ou não na ocorrência da mudança organizacional;

d. como o papel da liderança se faz crucial na prevenção, promoção ou permissão do aprendizado organizacional.

A partir destes pontos, a autora expóe uma série de fatores que condicionam a conclusão do processo de aprendizado organizacional, em uma tentativa de dimensionar as causas para as falhas de desenvolvimento da mudança organizacional, ampliando assim o debate no âmbito teórico aplicado, especialmente considerando o contexto estadunidense de melhorias de processos. Estes, a saber, seriam basicamente dois: processo top-down, de forma que a partir da teoria e da experiência, as lições auferidas sejam incluídas como doutrina e, após este processo, incluídas na educação e no treinamento militares; processo bottom-up, revisto após o período da Guerra Fria, e no qual tanto os processos formais de conhecimento e aprendizado (doutrina, educação e experiência coletiva), quanto os processos informais (experiência pessoal, comunidades de práticas e doutrina informal) são meios de canalizar seus componentes até os oficiais militares, agentes do processo de mudança organizacional.

Assim sendo, como diferencial, a abordagem apresentada pela autora tenta capturar como as estruturas institucionais internas e processos podem ou não promover a mudança militar através do aprendizado, sugerindo em seu estudo que os sistemas organizacionais projetados para captar e disseminar novas liçôes a partir da experiência podem agir como um contraponto para a resistência à mudança presente na cultura organizacional. Entretanto, a limitação da perspectiva de Davidson (2010) se encontra na crença de que a experiência consiste em uma variável determinante, especialmente nas modalidades de aprendizado geracional e experimental, de forma que, apesar de a autora apresentar a capacidade de adaptação a partir do aprendizado e da mobilização militar em períodos de conflito, ela não menciona uma maneira independente de difundir o aprendizado em períodos de paz, vinculando sua abordagem de maneira mais específica aos Estados Unidos e seu exército ao invés de constituir uma proposta de análise que abranja outros cenários se aplicada de maneira independente.

\section{A inovação militar vista de maneira integrada}

As teorias integradas sobre inovação militar são diversas, seja em termos de contexto, seja no que diz respeito às variáveis dependentes. Apesar das diferenças de enfoque, a base comum de todas é seu aspecto agregador na estruturação da abordagem, incluindo contextualização para a análise da inovação militar.

Primeiramente, como abordagem mais recente em relação às demais que pretendemos ilustrar, temos Horowitz (2007), que se desdobra tanto na explicitação da importância das inovaçóes militares, quanto em sua difusão. O foco de sua análise é como as inovaçóes militares são adotadas e difundidas por meio da "teoria da capacidade de adoção", de modo a:

“[...] prever não apenas o que determina o interesse do Estado em termos de inovaçóes, mas a capacidade do Estado de adotar inovaçóes, as outras escolhas estratégicas para os Estados frente as inovaçóes e as enormes consequências para o balanço de poder e a guerra que fluem a partir de mudanças nos requisitos 
de capacidades de adoção para métodos chaves de geração de poder militar"6 (Horowitz, 2007, p. 6).

Nesse sentido, o autor se opóe à acepçáo de que o emprego da tecnologia seja um determinante único para a conduta das novas formas de guerra. Horowitz ainda define a difusão como "o processo pelo qual uma inovação é comunicada por meio de certos canais ao longo do tempo entre os membros de um sistema social" (Horowitz, 2007, p. 9).

Adicionalmente, Horowitz estabelece que o paradigma da capacidade de adoção compreende que a difusão do poder militar entendido como uma combinaçáo de tecnologia ou equipamentos empregados em combate e os processos organizacionais - é regida por dois fatores:

a. o nível de intensidade financeira requerido para adotar a inovação militar;

b. o montante de transformaçấo organizacional requerido para adotar a inovaçáo. Em outras palavras, seria a mobilização de recursos em conjunto com a habilidade do Estado para dar apoio no setor financeiro e o que o autor definiu como "capital organizacional”. Esse último conceito apresenta três fatores-chave, que são:

1. a quantidade de recursos destinados à experimentação;

2. a inércia das organizaçôes militares como variável determinante para o desenvolvimento de inovaçóes integradoras;

3. as atribuiçôes críticas definidas pelas organizaçóes militares como variável determinante para a adoção de inovaçóes.

Com efeito, o propósito básico da abordagem de Horowitz (2007) portanto, é mensurar a capacidade dos Estados de implementar as inovaçóes (e não o interesse deles nestas), de modo que a escolha pela adoção da inovação militar ou de sua contenção é do Estado, tendo reflexos sistêmicos de ordem externa. A principal limitaçáo desta abordagem seria conceitual, posto que falta uma definiçáo mais apurada do conceito de "capital organizacional”. Como esta seria a principal variável para se mensurar a capacidade dos Estados em adotar as inovaçóes, ela se faz pouco clara na medida em que está perigosamente próxima de uma tautologia - questáo criticada mais adiante por autores como Stulberg, Salomone e Long, (2007). Os ganhos a partir da estrutura apresentada na teoria da adoção são justamente os de acontecimentos em nível sistêmico, abrindo a "caixa-preta" das inovaçóes tecnológicas e fornecendo um aporte crítico.

A abordagem de Posen (1986) se ocupa de demonstrar a importância da doutrina militar como vetor organizacional das forças armadas da Rússia, França e Alemanha, em coordenaçáo com suas respectivas políticas externas e diferentes graus de inovação. Sua abordagem mescla teorias das organizaçóes e de balança de poder para compreender as diferentes inclinaçóes do Estados a inovar suas doutrinas e as implicaçōes no cenário internacional. Por isso, aponta-se que sua contribuição constrói uma ponte entre os estudos de relaçóes internacionais e a aplicação da doutrina militar em estudos de caso comparados.

Snyder (1989, p. 9) também parte de uma perspectiva que contempla a doutrina militar, mas a ênfase de sua análise habita na estratégia, de forma que o autor delimita a doutrina estratégica da Alemanha, França e Rússia em termos de "cálculo racional, ilustrando a necessidade de simplificar decisóes complexas" especialmente no meio político. $\mathrm{O}$ autor delimita hipóteses acerca das fontes da doutrina 
estratégica por meio de teorias cognitivas e organizacionais baseadas na tomada de decisóes, estabelecendo o contexto em que emergem as posiçóes ofensiva ou defensiva adotadas pelos Estados. Os pontos de proximidade entre Posen (1986) e Snyder (1989) são basicamente o ponto de partida da análise, a doutrina militar e a utilizaçáo de aspectos da teoria organizacional em suas análises - especialmente na tomada de decisóes - em busca de delimitar as fontes para a doutrina.

Já em termos de diferenças, Posen (1986) depreende que a importância da doutrina militar emerge ao passo em que ela afeta a estabilidade do sistema internacional. Utilizando o prisma da teoria organizacional, o autor detecta que a tecnologia e a geografia possuem um papel secundário na doutrina militar. A compreensão de Snyder (1989), por outro lado, considera a estabilidade estratégica, de maneira que a identificaçấo de tecnologias e o pano de fundo geográfico não apenas favorecem a posiçấo ofensiva ou defensiva, mas também propóe que tais fatores devem ser analisados em termos de percepção entre rivais.

Especificamente, as limitaçóes da abordagem de Posen (1986) encontram-se no fato de que as fontes para a formulação das doutrinas e seu emprego não são completamente conclusivas dada a quantidade de variáveis às quais sua formulação se encontra exposta. Sob o prisma da teoria organizacional, apregoada pelo autor, as organizaçôes militares tenderiam a se comportar de forma contrária aos interesses do Estado, sendo pouco afetadas pela questão tecnológica, enquanto, sob o prisma da teoria de balanço de poder, náo se observa esse fenômeno. $\mathrm{O}$ uso de perspectivas teóricas não complementares entre si torna difícil extrair o pensamento geral do autor: é pouco conclusivo qual aporte teórico apresentado - teoria organizacional ou teoria de balanço de poder - elucida melhor quais questóes e relaçôes causais. A título de exemplo: o porquê de as mudanças serem pouco ou menos incidentes quanto ao armamento nuclear.

Já as limitaçôes da abordagem de Snyder (1989) encontram-se no fato de ela depender de particularidades de cada caso, dificultando a aplicação da abordagem em âmbito geral. Ademais, ao ressaltar o viés que predominantemente culmina na opção por uma estratégia ofensiva, o autor se baseia em um conceito vago, como "sabedoria prevalecente" (Snyder, 1989, p. 216), o que, pelo visto, coloca em xeque a racionalidade e a preponderância do interesse do Estado sobre qualquer situação a fim de garantir sua posição no status quo internacional. Desta forma, apesar de advogar a necessidade de que a decisáo seja tomada em alinhamento com a doutrina estratégica adotada, a pouca consistência do conceito de "sabedoria prevalecente" traz a necessidade de uma abordagem complementar para que sua linha de raciocínio se sustente na análise.

Partindo por outros pontos de vista, mais norteados pela distinção de períodos, Rosen (1991) contextualiza os períodos de guerra e de paz, subdividindo estas questôes em dois domínios e três subtipos: comportamento social e humano, no qual pode ser observado o comportamento operacional no período de paz e no período de guerra; e inovação tecnológica, no qual se observa a construçáo de novos equipamentos. Lançando luz sobre questóes como a vitória e a dinâmica das relaçôes dentro das burocracias militares em períodos de paz, Rosen (1991, p. 20) apregoa que:

\footnotetext{
"Esta nova teoria deve ser traduzida em novas tarefas concretas que são realizadas todos os dias, seja na paz, seja na guerra. Novas missóes críticas devem ser
}

7 Tradução nossa. 
definidas, de forma que os soldados possam entender que bom ou mau desempenho destas tarefas será a medida para a eficiência de um oficial e determinará, por recompensa e punição, a forma que a comunidade vive [...]. Sem o desenvolvimento de novas tarefas críticas, as inovaçōes 'ideológicas' permanecem abstratas e podem não afetar a forma que a organizaçáo se comporta na realidade." ${ }^{8}$

Nesse sentido, a proposta do autor visa demonstrar quais são os desafios a serem vencidos nos domínios e subtipos mencionados anteriormente, agregando em suas conclusôes quais eram os papéis dos recursos, da inteligência e do controle civil na inovação militar, de forma que mudanças estruturais pudessem ser atingidas e a inovação pudesse ser incorporada de fato.

Entre as depreensóes do autor está que o desafio da inovaçáo em tempos de paz consiste em inserir práticas de uma nova forma de guerra, também promovendo mudanças na carreira para a promoção de oficiais juniores em conjunto com a legitimidade do encabeçamento por oficiais sêniores. Durante tempos de guerra, o desafio consiste na redefinição de medidas de efetividade estratégica e sua respectiva assimilaçáo, permitindo que o aprendizado ocorra em concomitância com o conflito. Quanto à inovação tecnológica, seu desafio seria o gerenciamento da incerteza em termos de emprego, efetividade e, particularmente, a capacidade tática do oponente, que nem sempre é uma variável conhecida.

A despeito de diversas outras consideraçóes acerca de alocação de recursos, inteligência e o papel desempenhado pelos civis na instauração das inovações, Rosen (1991) termina por construir uma formulação que possui natureza prospectiva e propositiva. Desvendam-se aqui os aspectos que cercam as instituiçóes militares, demonstrando que são mais do que instituiçôes burocráticas ou monolíticas, mas sim entidades que possuem diferentes comportamentos quando expostas a períodos de paz ou períodos de guerra. Contudo, a demarcaçáo de alguns conceitos pouco conclusivos como "medidas de efetividade estratégica", e "poderio militar" como medida de capacidade de inovação tecnológica terminam por conferir uma natureza mais prospectiva e menos analítica a despeito da estrutura contextual construída.

Por fim, dentre os autores aqui relacionados, Murray (1996) se destaca por compreender a inovaçáo militar em termos de processo, percebendo diversas variáveis dentro de um determinado contexto de relaçóes. Analisando o contexto do entreguerras e extraindo algumas percepçóes sobre o processo de implementação de tais inovaçóes, Murray (1996, p. 305) argumenta que "as inovaçôes militares que tiveram a maior influência foram aquelas que mudaram o contexto no qual a guerra ocorria". Ainda conforme o autor, estas consistem em mais do que incorporaçáo de equipamentos e alterações técnicas previstas em doutrina, práticas e na tática militar, mas sim em uma oferta de estrutura que se prove importante no campo de batalha. Logo, para o autor, relaçóes importantes na inovaçáo militar abrangem contexto, mudança tecnológica, estratégia, procedimentos, mudança operacional, operaçóes per se, equipamentos, mudança técnica e tática.

Além disso, Murray (1996) explicita que inovaçóes militares revolucionárias são exceçóes, prevalecendo as de caráter evolutivo. Principalmente estas últimas dependem de foco organizacional no processo como um todo e, gradualmente, podem levar a resultados muito diferentes devido à sua natureza cumulativa. 
Analisando os sucessos e falhas nas inovaçóes no período mencionado, Murray (1996) depreende que a especificidade nos problemas a serem resolvidos e o "trato" com a cultura militar foram determinantes para o sucesso, enquanto o esquecimento das liçôes fornecidas pela história e a rigidez nas organizaçóes militares foram determinantes para falhas. Assim, o autor conclui sua análise relacionando educação e a transmissão de valores de maneira integrativa dentro da organização militar como questóes essenciais para a efetividade das inovaçóes, em conjunto com outras consideraçóes mais específicas, tais como:

a. foco em uma estrutura realista por parte das forças armadas;

b. reflexões sobre o ritmo operacional e o número de exercícios militares realizados ao longo do ano;

c. meios para garantir que a incorporação de liçóes aprendidas de operaçóes sejam mais do que meras análises que validem a doutrina e os procedimentos vigentes;

d. reflexóes sobre medidas de efetividade claras em cada nível das forças;

e. reflexóes acerca do sistema educacional militar e seu papel na implementação das inovaçóes;

f. familiaridade com análises não lineares, de maneira que não haja apenas reengenharias que terminam por inviabilizar as inovaçóes, mas uma análise estrutural.

O aspecto que distingue Murray (1996) está no fato de ele incluir a mencionada visão de processo sobre as inovaçôes, argumentando que, a despeito do desenvolvimento tecnológico e suas implicaçóes na ciência e na matemática, não seria possível reduzir as diversas variáveis envolvidas no processo de inovação nas instituiçóes militares de maneira linear. No entanto, apesar de contar com diversas acepçóes até mesmo complementares à abordagem de Rosen (1991), o enfoque de Murray (1996) também demanda por informaçóes complementares que podem ser provenientes de estudos de caso ou mesmo de outras abordagens acerca de inovaçóes militares que sejam complementares.

\section{Uma revisão crítica da teoria organizacional}

Compreendendo estruturas de abordagem mais complexas, o paradigma da agência, que compreende a transformação militar como mudança intraorganizacional, é apresentado por Stulberg, Salomone e Long (2007), identificando seus padróes e contextualizando as diferentes abordagens organizacionais existentes a fim de estabelecer quais seriam as melhores práticas para gerenciar estes processos.

Apresentando os paradoxos de mudanças estruturais em organizaçóes militares, os autores identificam a dificuldade de inserção do planejamento perante a cultura, estrutura hierárquica e demais idiossincrasias da instituição militar, demonstrando complicaçóes no dimensionamento de impactos práticos que mudanças mais profundas poderiam trazer a essa esfera. Isso seria possível apenas por um processo dinâmico de tradução das visóes e experiências captadas na guerra, tanto no teatro de operaçóes quanto em outras camadas, visando resultados maduros, inovadores e a incorporação de novas tecnologias e métodos operacionais. Contudo, mesmo a propensão à mudança em circunstâncias extremas não seria suficiente para que um novo arranjo fosse instaurado sem resistências.

Tecendo críticas iniciais a duas classes de abordagens sobre a mudança organizacional - a saber, abordagens exógenas, em que a mudança nas forças armadas ocorre a partir de fatores externos, e abordagens endógenas, nas quais ocorre o inverso - os autores abrangem desde críticas ao argumento defendido por Rosen (1991), em que "subgrupos novatos, dissidentes ou 'missionários' livres 
do núcleo de interesses organizacionais, em alguns casos podem se tornar os principais condutores da mudança na força singular" 9 (Stulberg; Salomone; Long, 2007, p. 25) até críticas mais duras às abordagens da cultura e do aprendizado organizacional. Para os autores, é difícil determinar com precisão o que vem a ser o aprendizado organizacional e a cultura, bem como diferenciar tais componentes como meios de explicar a mudança organizacional, dado que os conceitos de "coesão de unidade", "padrôes aceitáveis de comportamento" e "crença organizacional" carecem de base mais firme. Conforme estes:

"[...] ideias e cultura são tratadas tipicamente como atributos idiossincráticos de uma organização. Isso circunscreve severamente a generalização e o valor preditivo destes conceitos através de diferentes sociedades, forças singulares e unidades. Em particular, as manifestaçôes comportamentais dos credos subjetivos e mentalidades que permeiam uma organização são extremamente difíceis de observar ou mensurar. Os esforços recentes para operacionalizar as definiçóes genéricas de fatores ideacionais e culturais são potencialmente tautológicos, uma vez que os fatores associados ao treinamento, experimentação, consenso, hierarquia e estratégia militar são tratados como atributos tanto de causa quanto de efeito na mudança organizacional" (Stulberg; Salomone; Long, 2007, p. 26-27).

Desse modo, os autores buscam elucidar basicamente quatro problemas normativos que permeiam a mudança organizacional das forças armadas e os debates apresentados por meio de uma revisão da teoria da agência de Feaver (2003). Os problemas ilustrados são:

a. a visão unidimensional dada às dimensóes e padróes da mudança militar (análise de um único elemento: tecnologia, doutrina, estratégia ou tática);

b. a incerteza intrínseca acerca da introdução de inovaçóes dentro de uma organização; c. a confusão entre aspectos funcionais e normativos das instituiçóes;

d. a visão totalmente linear da interface entre conceitos e ideias.

Os autores focaram seus esforços considerando que as variáveis no processo de mudança organizacional eram de natureza eminentemente interna, optando por compreender como se dáo os mecanismos desta natureza - agentes, subgrupos ou subunidades e mecanismos dados na relaçáo entre os níveis hierárquicos da instituição militar e como eles atingem determinadas capacidades e impactam as mudanças de dentro para fora. Os pontos altos nesta formulação se materializam nas soluçóes das questóes normativas mencionadas anteriormente, apresentando um modelo funcionalmente explicativo sobre como se dá a dinâmica dentro de instituiçóes militares sem reduzi-las a um "todo" monolítico ou calcado em um aspecto único para propulsionar ou refletir a transformação militar.

Contudo, apesar de as críticas dos autores possuírem diversos argumentos consistentes, estas perdem parte de seu vigor na falta de contexto, uma vez que os estudos apontados pelos autores - focados em Estados Unidos, Reino Unido e Alemanha - consistem em casos que não variam exatamente pensando em um contexto macro; isto é, os estudos de caso apresentados pelos autores pertencem todos a Estados que participam ou participaram de guerras de forma mais ativa, permitindo que estes tenham acesso a um acumulado de conhecimento derivado de suas experiências, o que, por sua vez, permite que suas instituiçóes militares possam balizar os custos de implementar ou não mudanças organizacionais mediante o aprendizado. Logo, ao ignorar o fator contexto, que é bem demonstrado nas 
análises de Rosen (1991), os autores reduzem a questáo de sucesso da implementaçấo das inovaçôes às dinâmicas entre dirigentes e agentes dentro das instituiçóes militares, ignorando o peso causal da resistência à mudança organizacional representada por períodos de paz, ausência de contextos de conflitos diretos e da própria cultura e da identidade militar em termos intraorganizacionais, questóes passíveis de observação em localidades fora do eixo Europa-Estados Unidos.

Consequentemente, enquanto os autores apontam que o cerne dos problemas está na estrutura das relaçóes entre dirigentes (comandantes) e agentes (subordinados), e que a mudança organizacional não se restringe ao incremento orçamentário e alocação de recursos, é possível inferir casos em que a mudança é justamente implementada devido a constrangimentos na base orçamentária, agregando tal fator na tomada de decisão por um novo modelo organizacional. Portanto, ao retirar essas variáveis, os autores também incorrem na limitação de análise de forma similar ao que apontaram de forma crítica sobre os outros autores.

\section{Considerações finais}

A possibilidade de direcionamento das forças armadas fora do âmbito político e, por conseguinte, a serviço da sociedade, demanda um elenco de instrumentos que orientem as reformas das organizaçóes militares, bem como a manutenção de tais reformas com atribuiçóes determinadas ao longo do tempo. Esta é uma atribuição inescapável de qualquer república democrática, que deve ser servida pelas ciências sociais de maneira a qualificar seus tomadores de decisão e políticas para as forças armadas.

Para fins de ilustraçáo das abordagens aqui tratadas, incluímos um quadro-resumo comparativo (Quadro 1), resgatando os principais pontos abordados pelos autores, semelhanças e diferenças.

Quadro 1. Resumo das abordagens organizacionais e seus aspectos chave.

\begin{tabular}{|c|c|c|}
\hline Categoria de abordagem & Autor & Conceitos-chave \\
\hline \multirow[t]{2}{*}{ Cultura organizacional } & Nagl (2002) & $\begin{array}{l}\text { - Essência da organizaçáo } \\
\text { - Cultura organizacional } \\
\text { - Aprendizado institucional } \\
\text { - Memória institucional } \\
\text { - Personalidade organizacional } \\
\text { - Doutrina }\end{array}$ \\
\hline & Kier (1996) & $\begin{array}{l}\text { - Doutrina } \\
\text { - Cultura organizacional } \\
\text { - Pensamento militar }\end{array}$ \\
\hline \multirow[t]{2}{*}{ Burocracia política } & $\begin{array}{l}\text { Halperin, Clapp e Kanter } \\
(2006)\end{array}$ & $\begin{array}{l}\text { - Essência organizacional } \\
\text { - Imagem compartilhada } \\
\text { - Processo burocrático } \\
\text { - Política externa }\end{array}$ \\
\hline & Allison e Zellikow (1996) & $\begin{array}{l}\text { - Política governamental } \\
\text { - Resultantes políticas } \\
\text { - Negociaçáo de interesses } \\
\text { - Mecanismos burocráticos }\end{array}$ \\
\hline
\end{tabular}


Quadro 1 - continuação

\begin{tabular}{|c|c|c|}
\hline Categoria de abordagem & Autor & Conceitos-chave \\
\hline \multirow[t]{6}{*}{$\begin{array}{l}\text { Mudança } \\
\text { organizacional como } \\
\text { aprendizado }\end{array}$} & Kolb e Kolb (2008) & $\begin{array}{l}\text { - Processo de aprendizado } \\
\text { - Aprendizado experimental } \\
\text { - Integração } \\
\text { - Ciclo de aprendizado }\end{array}$ \\
\hline & DiBella $(2010,2013)$ & $\begin{array}{l}\text { - Aprendizado organizacional } \\
\text { - Orientaçóes de aprendizado } \\
\text { - Estilo de aprendizado } \\
\text { - Mudança organizacional }\end{array}$ \\
\hline & Davidson (2010) & $\begin{array}{l}\text { - Aprendizado organizacional } \\
\text { - Bottom-up review } \\
\text { - Mudança militar }\end{array}$ \\
\hline & Segal e Segal (1983) & $\begin{array}{l}\text { - Racionalização } \\
\text { - Indivíduo } \\
\text { - Modelo tradicional } \\
\text { - Modelo orgânico } \\
\text { - Psicologia } \\
\text { - Economia } \\
\end{array}$ \\
\hline & Senge (1994) & $\begin{array}{l}\text { - Pensamento sistêmico } \\
\text { - Complexidade de detalhes } \\
\text { - Complexidade dinâmica } \\
\text { - Gestão }\end{array}$ \\
\hline & $\begin{array}{l}\text { Baird, Henderson e Watts } \\
\text { (1997) }\end{array}$ & $\begin{array}{l}\text { - Recursos humanos } \\
\text { - Aprendizado } \\
\text { - Revisão de processos } \\
\text { - Estrutura de aprendizado e avaliaçáo }\end{array}$ \\
\hline $\begin{array}{l}\text { Mudança a partir da } \\
\text { Doutrina }\end{array}$ & Snyder (1989) & $\begin{array}{l}\text { - Doutrina } \\
\text { - Teoria organizacional } \\
\text { - Cálculo racional } \\
\text { - Estratégias ofensiva e defensiva }\end{array}$ \\
\hline \multirow[t]{4}{*}{ Inovação Militar } & Posen (1986) & $\begin{array}{l}\text { - Doutrina } \\
\text { - Teoria organizacional } \\
\text { - Balanço de poder } \\
\text { - Caráter da doutrina } \\
\text { - Inovaçấo como processo }\end{array}$ \\
\hline & Rosen (1991) & $\begin{array}{l}\text { - Inovação tecnológica } \\
\text { - Períodos de paz e de guerra } \\
\text { - Efetividade estratégica } \\
\text { - Poderio militar }\end{array}$ \\
\hline & Murray (1996) & $\begin{array}{l}\text { - Inovação como processo } \\
\text { - Inovaçốes evolutivas } \\
\text { - Cultura militar } \\
\text { - Educação } \\
\text { - Medidas de efetividade }\end{array}$ \\
\hline & Horowitz (2007) & $\begin{array}{l}\text { - Capacidade de adaptação } \\
\text { - Inovaçóes militares } \\
\text { - Capital organizacional }\end{array}$ \\
\hline
\end{tabular}


Quadro 1 - continuação

\begin{tabular}{l|l|l}
\hline Categoria de abordagem & \multicolumn{1}{|c}{ Autor } & \multicolumn{1}{c}{ Conceitos-chave } \\
\hline Revisão crítica das & Stulberg, Salomone e & - Transformação militar \\
teorias organizacionais & Long (2007) & - Gestão \\
& & - Interação estratégica \\
& & - Dirigentes \\
& - Agentes \\
& & - Inovaçáo como traço organizacional \\
\hline
\end{tabular}

Fonte: elaboração própria com base em Pessoa (2017).

Esta breve revisão bibliográfica compreende as diferentes abordagens presentes na teoria organizacional aplicada às forças armadas, desde as mais lineares, até as mais inseridas nas dinâmicas de processo. Em um esforço breve e, portanto, náo exaustivo, buscamos demonstrar a estrutura e a funcionalidade de cada uma das abordagens, apresentando suas principais premissas, bem como suas limitações. A estrutura das proposiçôes teóricas permite que o analista consiga observar com maior acuidade o objeto de estudos eleito, de forma que a elaboração de uma teoria compreensiva acerca da mudança organizacional no âmbito militar que abarque com sucesso todos os problemas envolvidos é um desafio ainda impossível de ser cumprido.

Desse modo, a comparação entre as abordagens de teoria organizacional, realizadas em conjunto com observaçóes de suas respectivas limitaçóes, se deu no sentido de demonstrar que parte significativa delas se estrutura de forma diretamente dependente dos estudos de caso escolhidos, apresentando limitaçóes na aplicação a outros contextos. Este é um ponto de reflexão importante se formos transportá-las para nossa realidade. Ainda assim, estas se constituem como ferramentas possíveis de ilustração de vários desafios atinentes a mudanças e gestão de organizaçóes militares em um ambiente de crise político-institucional, como a observada contemporaneamente no cenário brasileiro.

Ademais, as abordagens sistêmicas possuem maior potencial de uso em casos variados, mas também requerem emendas conceituais. Em que se pese, todas trazem contribuiçóes plausíveis para produção de análises e gestão de instituiçôes militares e, com as devidas complementaçóes e contextualizaçóes, ampliaremos o leque deste campo de estudos com leituras à brasileira.

Dentre as abordagens cuja tentativa de planificar o processo de mudança organizacional se fez evidente, destaca-se a grande maioria dos autores mencionados, a saber: Allison e Zelikow (1999); Baird, Henderson e Watts (1997); Davidson (2010); DiBella (2010, 2013); Halperin, Clapp e Kanter (2006); Horowitz (2007); Kier (1996); Nagl (2002); Murray (1996); Posen (1986); Rosen (1991); Segal e Segal (1983) e Stulberg, Salomone e Long (2007). Apesar de cada abordagem iluminar um aspecto preponderante no processo de mudança organizacional nas instituiçóes militares, todas conferem maior nitidez neste aspecto em particular, seja via cultura, doutrina e aprendizado. Todas essas abordagens têm em comum serem demasiadamente estruturalistas, tomando como dado os agentes e suas inter-relaçóes, sem aprofundamento sobre o contexto em que mudanças acontecem em organizaçóes militares. Por outro lado, dentre as abordagens sistêmicas, como as apresentadas por Kolb e Kolb (2008) e por Senge (1994), existe um predomínio de interesse pela estrutura geral e pelas inter-relaçóes que compóem o processo do aprendizado organizacional de forma geral, revelando preocupação com a imagem como um todo e náo seus aspectos particulares. 
A tensão entre a visualização de uma variável como determinante nas abordagens mais planificadas e a visualização do processo em termos de estrutura, permitindo um maior afastamento em relação ao determinismo de variáveis visualizadas de forma isolada, se faz evidente. Cada visão demonstra um grau de afastamento variado e permite a observação de diferentes imagens quanto à caracterização do processo de mudança organizacional, conferindo versatilidade e oferecendo mais caminhos possíveis ao analista.

Por fim, compreendemos que há muito o que se desenvolver em termos de pesquisa, especialmente quanto à saga da gestão das relaçóes civis-militares em contextos de crise do Estado. Entre pontos de concordâncias e discordância, trazemos aqui uma questáo fundamental quanto aos indivíduos que lapidam estas mudanças: as diferenças - que também podem ser pontos de agregação - entre civis e militares.

A escolha de abordagem teórica ou mesmo este esforço de revisão sobre abordagens organizacionais consiste em um passo pequeno diante de toda uma série de desafios que se interpóem na consideração das forças armadas enquanto campo de estudo necessário para materialização das mudanças organizacionais rumo aos objetivos de preservaçáo da democracia e da defesa nacional. Respondendo à questão que fizemos no título, sim, instituiçóes militares aprendem, evoluem e se modificam. Ainda assim, os objetivos, os conteúdos e a retenção deste aprendizado requerem considerável planejamento, investimento e controle. Mais que isso, tal processo não é linear nem contínuo e depende muito de contextos sociais, internos e externos, das organizaçóes militares. Portanto, deve receber mais e mais atenção das ciências sociais como um todo. Espera-se que esta breve revisão bibliográfica contribua para a evolução dos debates acadêmico e público sobre relaçóes civis-militares e forças armadas no Brasil. Isso é diuturnamente premente em tempos em que o tensionamento dessas relaçóes escalonam e colocam sob suspeita o porvir da democracia brasileira.

\section{Referências}

ALLISON, G.; ZELIKOW, P. Essence of Decision: Explaining the Cuban Missile Crisis. New York: Addison-Wesley, 1999.

BAIRD, L.; HENDERSON, J. C.; WATTS, S. Learning from action: An analysis of the center for army lessons learned (CALL). Human Resource Management, v. 36, n. 4, p. 385-395, 1997. https://doi.org/10.1002/ (SICI)1099-050X(199724)36:4\%3C385::AID-HRM3\%3E3.0.CO;2-R

BARANY, Z. The Soldier and the Changing State: Building Democratic Armies in Africa, Asia, Europe, and the Americas. Princeton: Princeton University Press, 2012.

BIDDLE, S. D. Military Power: Explaining Victory and Defeat in Modern Battle. Princeton: Princeton University Press, 2006.

BROOKS, R. A.; STANLEY, E. A. (org.). Creating Military Power: The Sources of Military Effectiveness. Redwood City: Stanford University Press, 2007.

BRUNEAU, T. C. A conceptual framework for the analysis of civil-military relations and intelligence. Defense and Security Analysis, v. 34, n. 4, p. 345-364, 2018. https://doi.org/10.1080/14751798.2018.1529085 
BUZAN, B.; LITTLE, R. International Systems in World History: Remaking the Study of International Relations. Oxford: Oxford University Press, 2000.

COSTA, A. T. M. O lobby militar e as relaçóes civis-militares durante a Assembléia Nacional Constituinte. Dissertação (Mestrado em Ciência Política) - Universidade de Brasília, Brasília, 1998.

DAVIDSON, J. Lifting the Fog of Peace: How Americans Learned to Fight Modern War. Ann Arbor: University of Michigan Press, 2010.

DIBELLA, A. J. Can the Army Become a Learning Organization? A Question Reexamined. Joint Forces Quarterly, n. 56, p. $117-122,2010$.

DIBELLA, A. J. Organization theories: perspectives on changing national security institutions. Joint Forces Quarterly, n. 69, p. 13-19, 2013.

FEAVER, P. D. Armed Servants: Agency, Oversight and Civil-Military Relations. Cambridge: Harvard University Press, 2003.

FEAVER, P. D. Civil-military relations and policy: a sampling of a new wave of scholarship. Journal of Strategic Studies, v. 40, n. 1-2, p. 325-342, 2017.

HEBDITCH, D.; CONNOR, K. How to Stage a Military Coup: From Planning to Execution. New York: Skyhorse, 2009.

HALPERIN, M. H.; CLAPP, P. A.; KANTER, A. Bureaucratic Politics and Foreign Policy. 2. ed. Washington, DC: Brookings Institution Press, 2006.

HOROWITZ, M. C. The Diffusion of Military Power: Causes and Consequences for International Politics. Tese (Doutorado) - Harvard University, Cambridge, 2007.

HUNTINGTON, S. P. The Soldier and The State: the theory and politics of civil-military relations. Cambridge: Harvard University Press, 1956.

KADERCAN, B. Strong armies, slow adaptation: civil-military relations and the diffusion of military power. International Security, v. 38, n. 3, p. 117-152, 2014.

KIER, E. Culture and French military doctrine before World War II. In: KATZENSTEIN, P. (ed.). The Culture of National Security: norms and identity in world politics. New York: Columbia University Press, 1996. p. 186-215.

KOLB, A. Y.; KOLB, D. A. Experiential learning theory: a dynamic, holistic approach to management learning, education and development. In: ARMSTRONG, S. J.; FUKAMI, C. V. (ed.). Handbook of Management Learning, Education and Development. Thousand Oaks: Sage, 2008. p. 42-68.

LIBEL, T. The advanced command and staff course (ACSC): the first ten years. Buletinul Universităţii Naţionale de Apărare "Carol I", n. 2, p. 45-56, 2010. 
LUTTWAK, E. N. Coup d'État: a practical handbook. 2. ed. Cambridge: Harvard University Press, 2016.

MURRAY, W. Innovation - Past and future. In: MURRAY, W.; MILLETT, A. R. (ed.). Military Innovation in the Interwar Period. Cambridge: Cambridge University Press, 1996. p. 300-328.

NAGL, J. A. Counterinsurgency Lessons From Malaya and Vietnam: learning to eat soup with a knife. Westport: Praeger, 2002.

PESSOA, T. S. A formaçáo de oficiais e as operaçóes conjuntas : comparaçôes com o caso britânico e os desafios brasileiros de gestáo em defesa. Tese (Doutorado em Estudos Estratégicos Internacionais) - Universidade Federal do Rio Grande do Sul, Porto Alegre, 2017.

PESSOA, T. S.; DUARTE, E. E. Defense management $\&$ defense analysis: desafios para o ministério da defesa. In: ARTURI, C. A. (org.). Políticas de defesa, inteligência e segurança. Porto Alegre: UFRGS: CEGOV, 2014. p. 114-146.

PION-BERLIN, D.; DUDLEY, D. Civil-Military relations: what is the state of the field. In: SOOKERMANY, A. M. (ed.). Handbook of Military Sciences. New York: Springer Cham, 2020. p. 1-22.

POSEN, B. R. The Sources of Military Doctrine: France, Britain, and Germany between the world wars. Ithaca: Cornell University Press, 1986.

PROENÇA JÚNIOR, D. Forças armadas para quê? Para isso. Contexto Internacional, v. 33, n. 2, p. 333-373, 2011. https://doi.org/10.1590/S0102-85292011000200004

RAGIN, C. C. La construcción de la investigación social: introducción a los métodos y su diversidad. Bogotá: Siglo del Hombre, 2007.

RATCHEV, V. Civilianisation of the Defence Ministry: a functional approach to a modern defence institution. Geneva: DCAF, 2011.

ROSEN, S. P. Winning the Next War: innovation and the modern military. Ithaca: Cornell University Press, 1991.

SEGAL, D. R.; SEGAL, M. W. Change in military organization. Annual Review of Sociology, v. 9, n. 1, p. 151-170, 1983. https://doi.org/10.1146/annurev.so.09.080183.001055

SENGE, P. M. The Fifth Discipline: the art and practice of the learning organization. New York: Currency Doubleday, 1994.

SILVA, L. H. R. da. A contribuiçáo dos conceitos da gestão da mudança para as relaçóes entre civis e militares no campo político-orçamentário. Dissertação (Mestrado em Administração Pública) - Fundação Getúlio Vargas, Rio de Janeiro, 2007.

SNYDER, J. The Ideology of the Offensive: military decision making and the disasters of 1914. Ithaca: Cornell University Press, 1989.

STUlberG, A. N.; SALOMONE, M. D.; LONG, A. G. Managing Defense Transformation Agency, Culture and Service Change. Abingdon: Routledge, 2007.

SYME-TAYLOR, V. Innovative teaching methods in military pedagogy. In: ANNEN, H.; WOLFGANG, R. (ed.). Educational Challenges Regarding Military Action. Frankfurt am Main: Peter Lang, 2010. p. 209-214. 


\section{Resumo}

Instituiçōes militares também aprendem? Uma revisäo bibliográfica sobre abordagens organizacionais na gestäo de defesa

Este artigo tem como objetivo apresentar uma revisão bibliográfica para alinhar a seara de relaçóes civis-militares com o conteúdo analítico e de prognósticos de teorias sobre mudança e aprendizado organizacionais possíveis de serem aplicadas em organizaçóes militares. $\mathrm{O}$ artigo expõe os presentes eixos de produção acadêmica, bem como os potenciais e limitaçóes de cada um deles. A contribuição que se busca é a de síntese e apresentação de ferramentas de análise que iluminem os diversos aspectos que constituem o processo de mudança organizacional no meio militar, desvendando algumas preconcepçóes existentes quanto a esta possibilidade para o caso brasileiro.

Palavras-chave: Gestão de defesa; Mudança organizacional; Aprendizado organizacional; Forças armadas; Relaçóes civis-militares.

\section{Abstract}

Do military institutions also learn? A literature review on organizational approaches to defense management

This article aims to present a bibliographic review to align the field of civil-military relations with the analytical and prognostic content of theories about organizational change and learning applicable to military organizations. By addressing the axes of academic production and their respective potentials and limitations, this article seeks to synthesize the analysis tools that illuminate the various aspects of organizational change within the military field, unveiling some existing preconceptions regarding this possibility for the Brazilian case.

Keywords: Defense management; Organizational change; Organizational learning; Armed forces; Civil-military relations.

\section{Résumé}

Les institutions militaires apprennent-elles aussi? Une revue de la littérature sur les approches organisationnelles pour la gestion de la défense

Cet article présente une revue de la littérature afin d'aligner le domaine des relations civiles-militaires avec le contenu analytique et les prédictions des théories du changement organisationnel et de l'apprentissage qui peuvent être appliquées aux organisations militaires. L'article présente les axes actuels de la production académique, ainsi que les potentiels et les limites de chacun d'entre eux. Cette recherche vise à synthétiser et présenter des outils analytiques qui éclairent les différents aspects constituant le processus de changement organisationnel dans l'armée, en dévoilant certains préjugés existants sur cette possibilité pour le cas brésilien.

Mots-clés : Gestion de la défense ; Changement organisationnel ; Apprentissage organisationnel ; Forces armées ; Relations civiles-militaires. 